\title{
Functional endoscopic sinus surgery (FESS) with navigation system in childhood - our experience. Presentation of clinical cases
}

\author{
B. Duhlenski, Al. Valkov, Tsv. Mladenov, M. Yulduz, G. Nikolov, \\ Tsv. Stoyanov, Kr. Atanasova \\ Department of Otorhinolaryngology, Faculty of Medicine, Medical University - Pleven, \\ 1 Kliment Ohridski Str., Pleven 5800 \\ Clinic of Otorhinolaryngology, University Hospital "Dr. Georgi Stranski" - Pleven, Il Clinical Base, \\ 91 Gen. Vladimir Vazov Str., Pleven 5800
}

\begin{abstract}
Introduction: Functional endoscopic sinus surgery (FESS) is the gold minimally invasive standard in diagnosing and surgically treating many diseases of the nose and paranasal cavities. An advantage of FESS is the possibility of application in all age groups.

Materials and methods: We observed pediatric patients attended the Otorhinolaryngology Clinic in the University Hospital "Dr. Georgi Stranski" - Pleven in 2021. FESS surgery was performed in the "Integrated interdisciplinary operating unit with navigation and telesurgery systems" at the Center of competence on personalised medicine, 3D and telemedicine, robotic and minimally invasive surgery „Leonardo da Vinci” in Medical University - Pleven.

Clinical cases: Case 1: A 7-year-old male patient with orbital complication of rhinosinusitis, with left orbital preseptal cellulitis, without ophthalmoplegia or loss of vision, + ptosis of the eyelid and data on pansinuitis from CT images. Performed FESS found lysis of lamina papyracea with involvement of anterior and posterior ethmoidal cells. Postoperative treatment was done with Ceftriaxone $1 \mathrm{~g} / 12 \mathrm{~h}$ i.v. for 7 days, nasal glucocorticoids and antihistamines.

Case 2: A 17-year-old female patient with suggested primary ciliary dyskinesia with a recurrent rhinosinusitis, persistent nasal obstruction, and thick viscous secretions that did not respond to conservative treatment. Sweat test for cystic fibrosis (-). FESS reshaping of the natural openings of the maxillary sinuses and anterior ethmoidectomy were performed bilaterally.

Conclusion: FESS is a minimally invasive method, which is suitable for application in pediatric patients. When applied by trained professionals, FESS with an integrated navigation system is optimal for the diagnosis and surgical treatment of chronic and acute rhinosinusitis in children.

Keywords: FESS, endoscopic surgery of the nose and sinuses, chronic rhinosinusitis, acute rhinosinusitis, pediatric patients.
\end{abstract}

This work was presented at the XV National Congress of Otorhinolaryngology, 05-07 November 2021, Borovets, Bulgaria.

This study was supported by Project BG05M2OP001-1.0020010-C01, "Center for Competence in Personalized Medicine, $3 D$ and Telemedicine, Robotic and Minimal Invasive Surgery" funded by the Operational Program "Science and Education for Smart Growth," co-funded by the European Union through the European Structural and Investment Funds".

\section{Introduction}

Functional endoscopic sinus surgery (FESS) with an integrated navigation system is a gold-standard minimally invasive method for surgical treatment of a variety of inflammatory and infectious diseases of the nose and nasal cavities with substantial evidence of effectiveness for chronic rhinosinusitis with or without polyps and recurrent acute rhinosinusitis. [1-7]. It is also a valuable modern approach to the surgical management of sinonasal malignancy, congenital tumors, polyposis with high-grade obstruction, mucocele, abscesses and other pathological processes in these anatomical areas.

The image-guided navigation strategy has optimized patient safety and recovery and has improved surgeon intraoperative accuracy and time for approaching the anatomical structures. [8-11] Among the advantages of FESS with an integrated navigation system is the possibility of application at any age, the improved intraoperative orientation and access to the affected area, the sparing of adjacent tissues and structures and the optimal timing of the short-term outcomes. [12-14] For beneficial treatment, symptoms should be precisely observed, and computer tomography (CT) scans of the nose and paranasal cavities meeting specific criteria should confirm the diagnosis. FESS is most commonly used to treat chronic sinusitis that does not respond to standard medical treatment.

In pediatrics, experts recommend considering sino-nasal surgery when children have documented 
four annual episodes of recurrent rhinosinusitis, and the previous maximum medical therapy (antibiotics, nasal glucocorticoids, antihistamines, nasal decongestants and clearing saline irrigations) or adenoidectomy have failed to control the disease. Suppurative complications of acute or chronic rhinosinusitis (brain abscess, meningitis, orbital abscess) are among the indications for eradication with FESS.

When taking decision for applying the method, otorhinolaryngology surgeons are advised to assess the presence and severity of signs and symptoms and the number and duration of pre-operative conservative treatments, and to observe the CT scan images and plain radiographs (when applicable, but less reliable in young children) showing the pathology of the affected area. The informed consent on the use of FESS should also include a discussion on the patient preferences about the surgical method.

This surgical technique is minimally invasive, but not absolutely lacking of complications. Side effects can vary in frequency, severity and time of onset (early and late) from mild complications like reversible hyposmia, periorbital ecchymosis, orbital emphysema, epistaxis and adhesions to more severe events like anosmia, nasolacrimal duct trauma or carotid injury. Severe complications are rare $(<0.5 \%)$ and presented by orbital and intracranial penetration, orbital hematoma, optic nerve damage, visual disturbances and irreversible blindness. Potentially life-threatening are the cerebrospinal fluid leakage, intracranial hemorrhage, cerebral infarction, pneumoencephalitis and meningitis. [15-17].

\section{Material and Methods}

Place of FESS operating room: Integrated interdisciplinary operating unit with navigation and telesurgery systems at II Base of the University Hospital "Dr. Georgi Stranski" - Pleven.

Clinical base: ORL Clinic at University Hospital "Dr. Georgi Stranski" Pleven.

Technical equipment and tools: (1) Olympus endoscopic processor OTV-S190, Olympus sinuscope, Trueview II optical telescope, mechanically adjustable sinuscope Telescope "V-DOV" and hand tool set; Olympus Celon Elite ProCut handpiece monopolar cutting handle, monopolar cutting forceps, gripping forceps, electrode for handle for monopolar cutting. (2) Navigation system Brainlab Kick 2.0 EM (3) Olympus 32-inch HDTV Medical Mon- itor FS and connected medical recorder for capture of full HD images and videos. (Fig. 1-3)

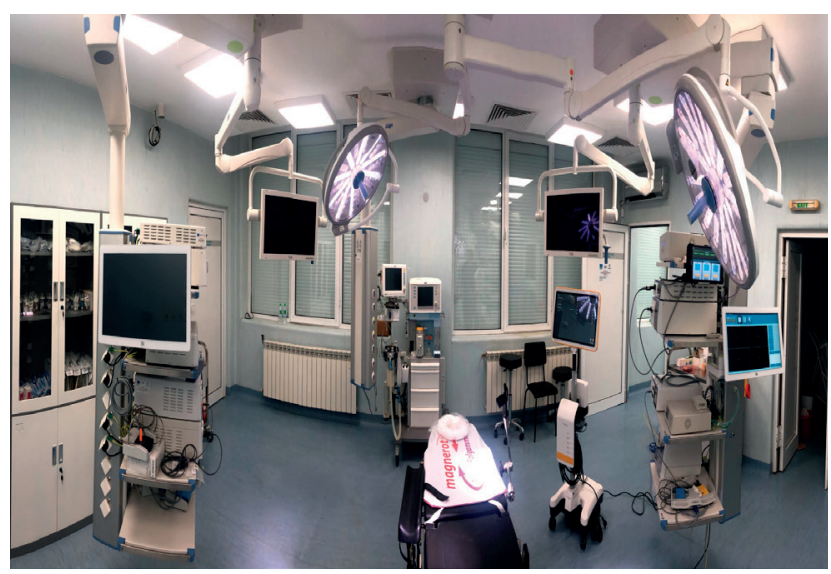

Fig. 1. Integrated interdisciplinary operating unit with navigation and telesurgery systems.

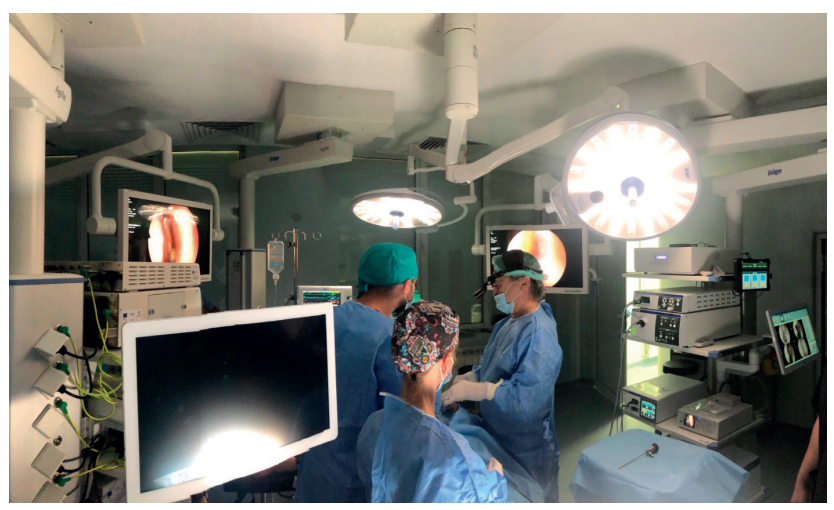

Fig. 2. Operating otorhinolaryngology unit.

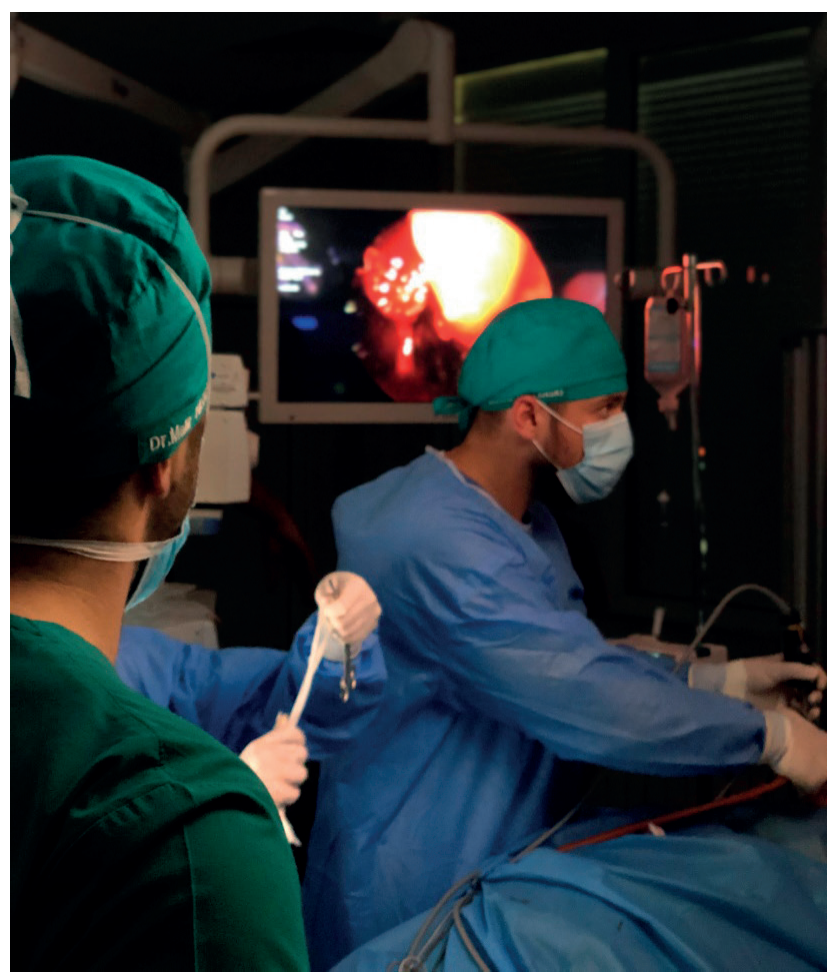

Fig. 3. Demonstration of FESS with navigation working process. 


\section{Results}

Case 1: A 7-year-old boy attended the clinic with an orbital complication of recurrent rhinosinusitis presented by 7-day lasting symptoms of stuffy nose and thick-secretion nasal discharge. The patient complained of left-eye oedema, lacrimation and head-heaviness developed three days before the

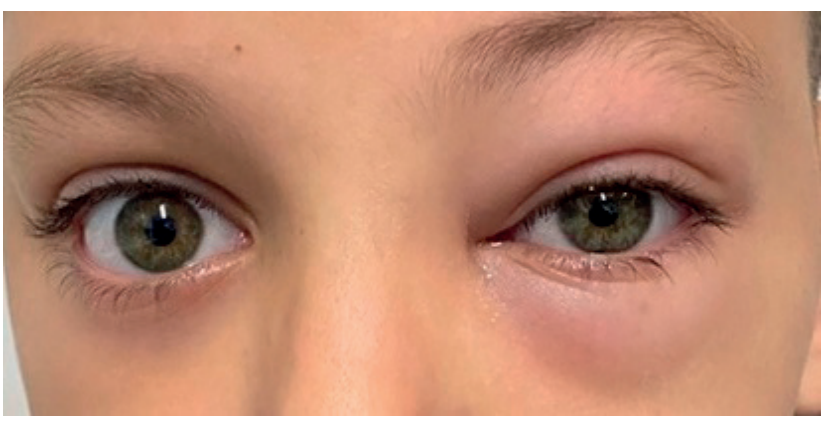

Case 1: a admission. The local status established oedematous left eye with orbital preseptal cellulitis, normal visual acuity and third-degree ptosis of the eyelid without ophthalmoplegia. (Fig. 4)

The pre-operatively done CT scan images showed data on pansinuitis. (Fig. 5.)

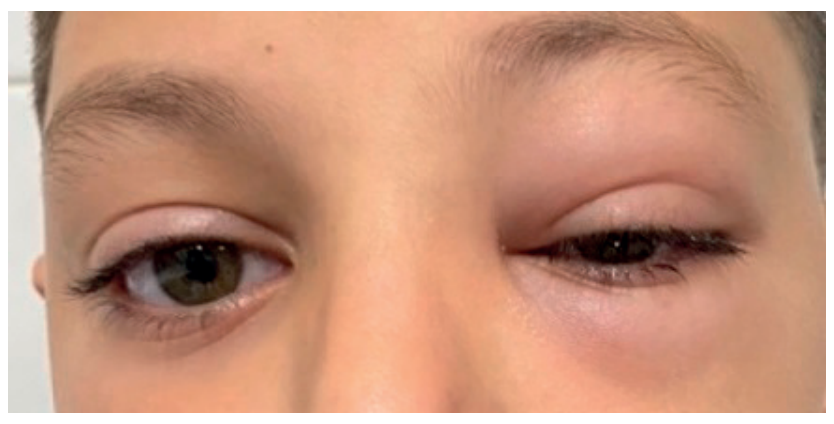

Case 1: b

Fig. 4. Case $1 \mathrm{a}, \mathrm{b}$ : Demonstration of periorbital edema and ptosis of the eyelid.

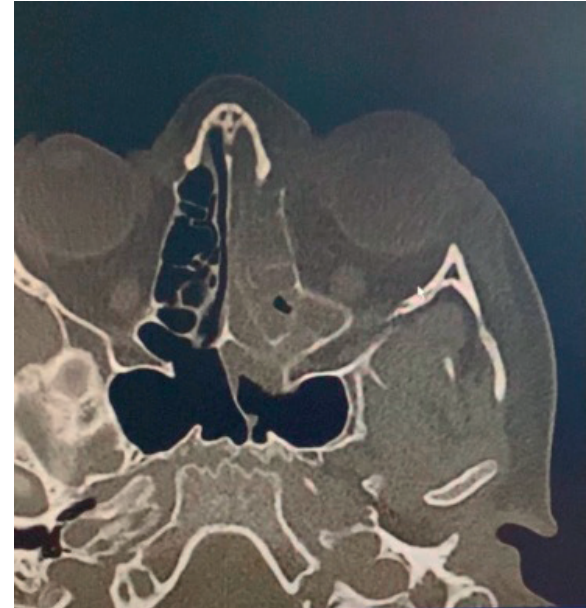

Case 1: a

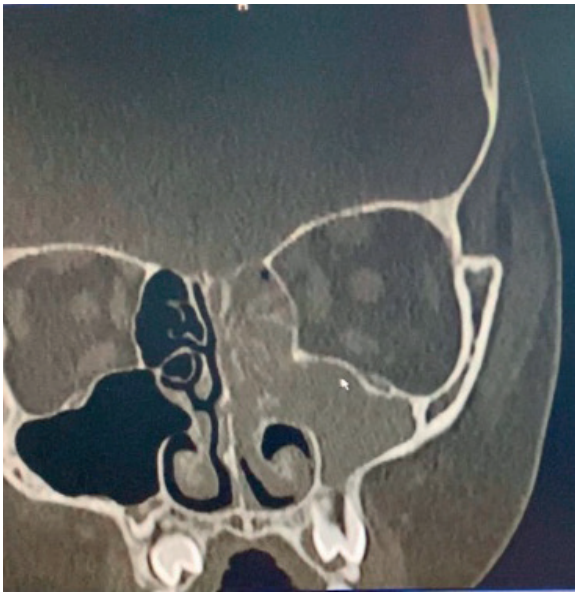

Case 1: c

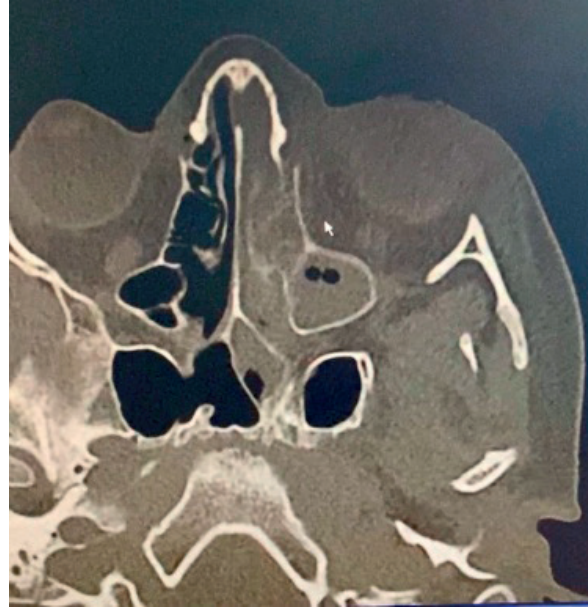

Case 1: b

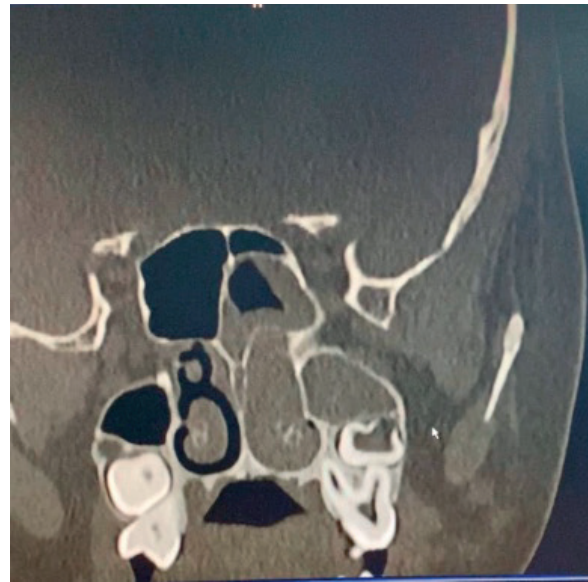

Case 1: d

Fig. 5. Case 1 a-d: Pre-operative CT images of the nose and paranasal cavities showing left orbital preseptal cellulitis. 
The performed FESS found lysis of lamina papyracea with involvement of anterior and posterior ethmoidal cells. The patient received 7-day postoperative pharmacotherapy with Ceftriaxone $1 \mathrm{~g} / 12 \mathrm{~h}$ i.v., nasal glucocorticoids and oral antihistamines. The full cycle of in-hospital treatment and ambulatory follow-up resulted in complete recovery. (Fig. 6)

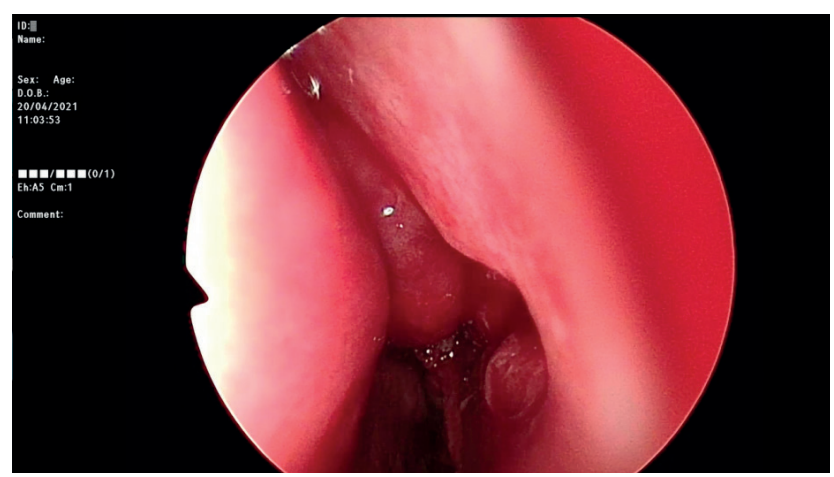

Case 1: e

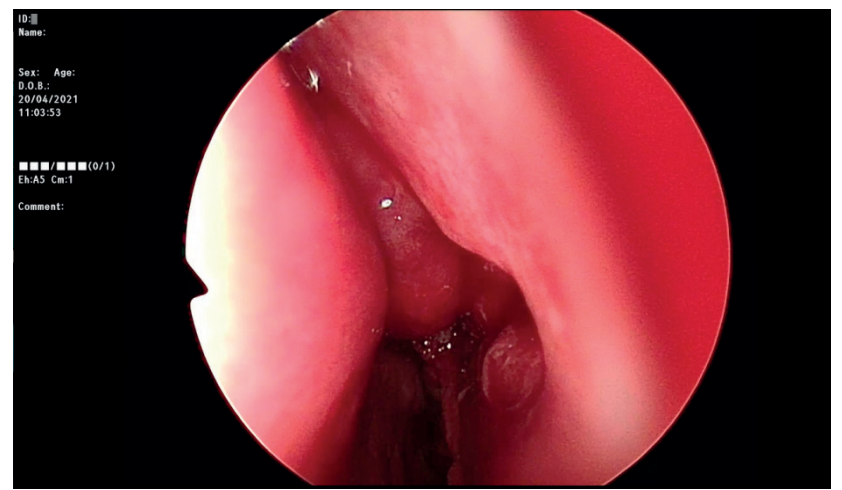

Case 1: f

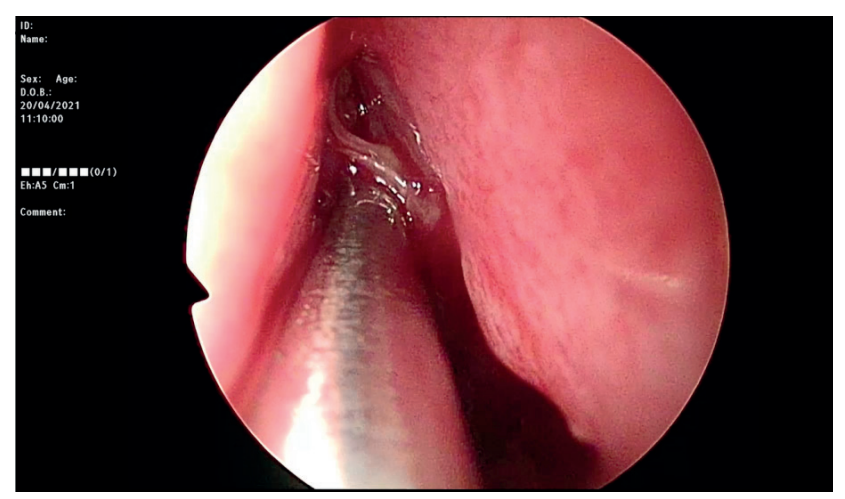

Case 1: $\mathrm{g}$

Fig. 6. Case 1 e-g: Performance of FESS.

Case 2: A 17-year-old girl presented to the clinic with a history of frequent rhinosinusitis, persistent nasal obstruction, and thick viscous secretions unaffected by repeated conservative treatment. The working diagnosis "chronic non-inflammatory non-infectious rhinosinusitis with suspected primary ciliary dyskinesia" was considered with assessment of plain radiographs and CT scan images. [18] (Fig. 7-8) Sweat test for cystic fibrosis was negative.

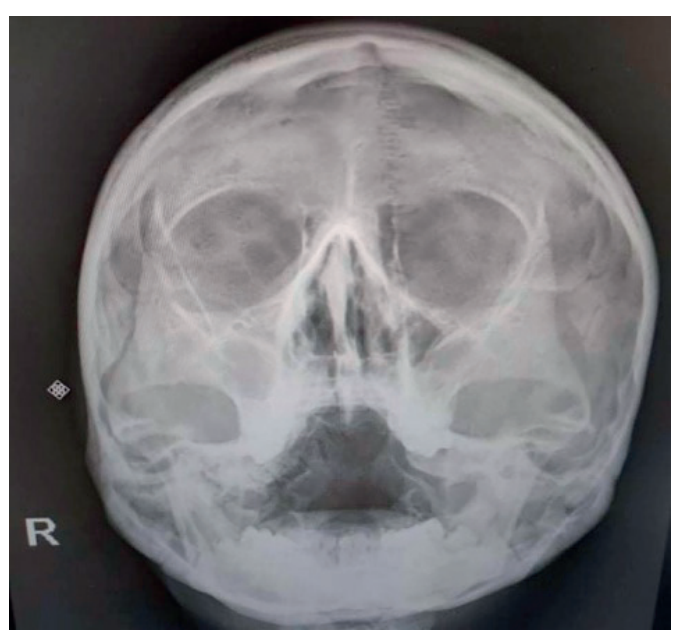

Fig. 7. Case 2: X-ray image of the sinuses.

We performed FESS with reshaping of the natural openings of the maxillary sinuses and anterior ethmoidectomy bilaterally. (Fig. 9)

Nasal corticosteroids, saline irrigations and oral antihistamines were prescribed for outpatient medical treatment. Performed control examinations established objective improvement in the local status. The patient reported significant symptom relief and reduction in troubling complaints.

\section{Discussion}

The demonstrated clinical cases and positive treatment outcomes correspond to the latest recommendations published by foreign and Bulgarian experts and stated by international and national guidelines and position papers on the use of FESS in pediatric patients. [19-24] Professional panels reported during the last decade have reached consensus regarding the usefulness of adenoidectomy for children up to 12-year age, but evidence is still controversially about the other pediatric groups of patients. Researchers concluded on the significantly better efficacy of FESS in the management of pediatric chronic rhinosinusitis compared to medical treatment and adenoidectomy respectively. Two systematic reviews also found high rates of optimal postoperative outcomes after using FESS in children. Pre-operative CT scan imaging is strongly ad- 


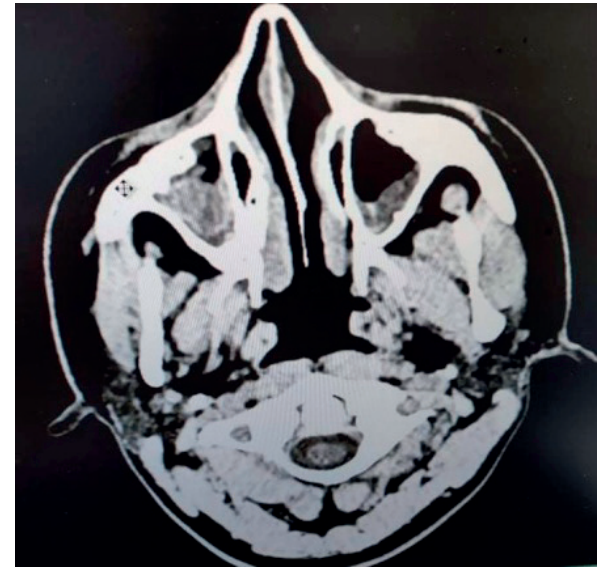

Case 2: a

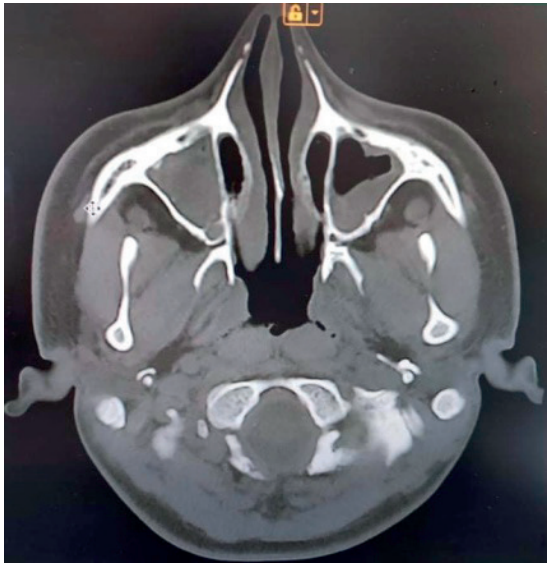

Case 2: b

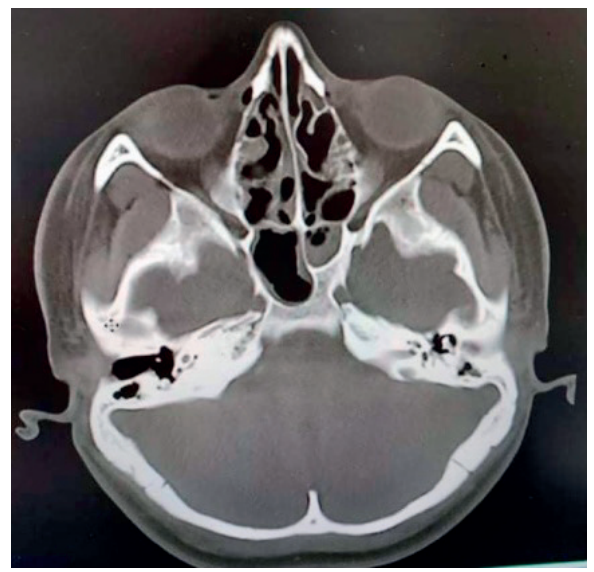

Case 2: c

Fig. 8. Case 2 a-c: CT images of the nose and paranasal cavities.

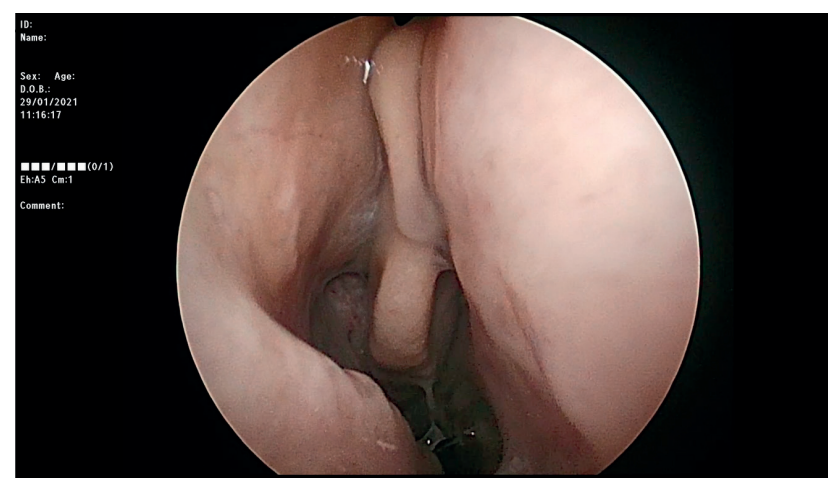

Case 2: d

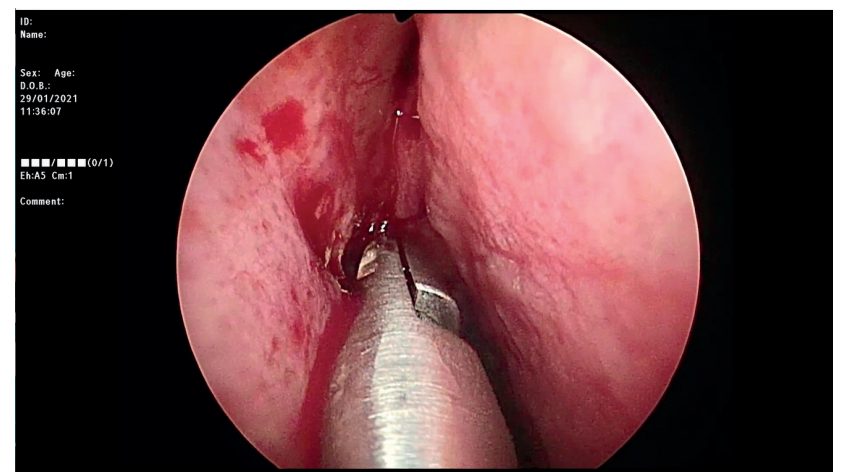

Case 2: $\mathbf{f}$

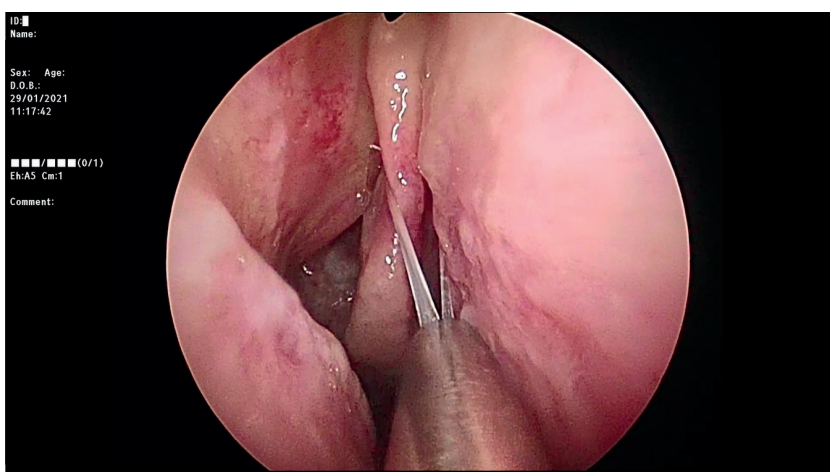

Case 2: e

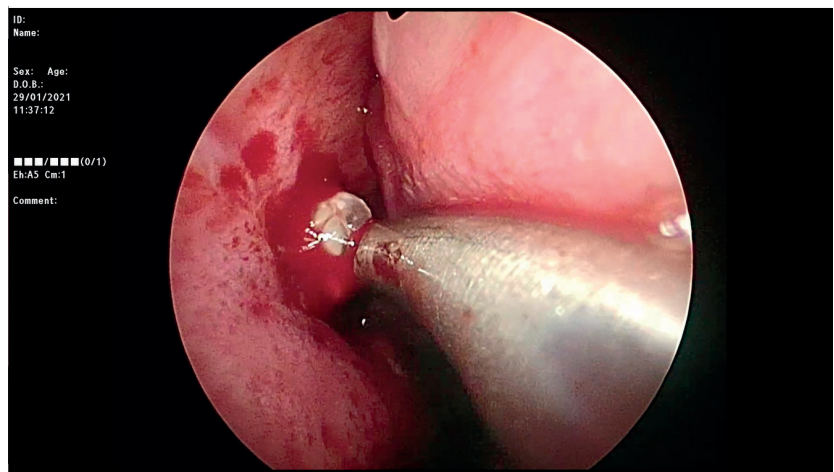

Case 2: $\mathbf{g}$

Fig. 9: Case $2 \mathrm{~d}-\mathrm{g}$ : Performance of FESS for reshaping of the natural openings of the maxillary sinuses and bilateral anterior ethmoidectomy.

vised for precise assessment of anatomy and pathological changes in the affected fields. [25]

\section{Conclusion}

Our study on the application of FESS with navigation in children with sino-nasal pathology supports the effectiveness of this minimally invasive method for a safer, more accurate and sparing sur- gical approach to the affected area and its benefit in treating children with acute recurrent or chronic rhinosinusitis and their serious complications. The overall assessment of the significance and applicability of the method in the regional otorhinolaryngology practice is the subject of forthcoming multidisciplinary studies within the project BG05M2OP001-1.002-0010. 


\title{
References:
}

1. Fokkens WJ, Lund VJ, Hopkins C, Hellings PW, Kern R, Reitsma S, et al. European position paper on rhinosinusitis and nasal polyps 2020. Rhinology 2020; 58 (Suppl.S29): 1-464. doi: 10.4193/Rhin20.601

1. Европейски консенсус за риносинуити и носна полипоза 2020. Изд. Българско Ринологично Сдружение, Пловдив, 2021. ISBN 978619-91274-2-1.

1. Functional Endoscopic Sinus Surgery (FESS). United Healthcare ${ }^{\circledR}$ 2021: 1-11. https://www.uhcprovider.com/content/dam/provider/docs/ public/policies/comm-medical-drug/functional-endoscopic-sinus-surgery.pdf

1. Wormald PJ. Endoscopic Sinus Surgery. Stuttgart, New York, NY: Thieme 2018. doi: 10.1055/b-0038-149997

1. Naidoo Y, Wen D, Bassiouni A, Keen M, Wormald PJ. Long-Term results after primary frontal sinus surgery. Int Forum Allergy Rhinol 2012; 2: 185- 90. doi: 10.1002/alr.21015

1. Tsuzuki K, Hashimoto K, Okazaki K, Sakagami M. Post-operative course prediction during endoscopic sinus surgery in patients with chronic rhinosinusitis. JLO 2018. doi:10.1017/S0022215118000543

1. Saxena A, Nekhendzy V. Anesthetic considerations for functional endoscopic sinus surgery: a narrative review. Journal of Head \& Neck Anesthesia 2020; 4(2): pe25. doi: 10.1097/HN9.0000000000000025

1. Dzambazov K, Markov S, Topalova A. Cerebrospinal fluid rhinorrhea - diagnostic methods review and clinical cases demonstration. International Bulletin of Otorhinolaryngology 2015; 3(11): 5-17.

1. Djambazov KB, Kitov BD, Zhelyazkov CB, Davarski AN, Topalova AR. Mucocele of the sphenoid sinus. Folia Medica 2017; 59(4): 481485. DOI: 10.1515/folmed-2017-0049

1. Zlatanov HK, Milev SM. FESS extraction of nasal foreign body in an adult patient - clinical case presentation [article in Bulgarian]. MB othorhinolaryngology 2010; 3: 18-21.

1. Zlatanov Hr, Milev S, Tzvetkov V. FESS for the management of orbital disease and complications. International Bulletin of Otorhinolaryngology 2015; 2(11): 14-19.

1. Agrawal M, Arya P, Meghwal D, Samor V, Gupta G, Kumar V. Role of navigation system in functional endoscopic sinus surgery. Int J Otorhinolaryngol Head Neck Surg 2020; 6(8): 1455-1459. http://dx.doi.org/10.18203/issn.2454-5929.ijohns20203204

1. Barber SR, Jain S, Son YJ, Chang EH. Virtual functional endoscopic sinus surgery simulation with 3d-printed models for mixedreality nasal endoscopy. Otolaryngol Head Neck Surg 2018; 159: 933-937. doi: 10.1177/0194599818797586

1. Mladenovski M, Vasilev N, Ovcharov M, Valkov I. Basic neuronavigation options for cortical and subcortical brain lesions surgery. JBCR 2018; 11(2): 141-149.

1. Amadei E. Functional endoscopic sinus surgery (FESS): Is it always a safe procedure? Otorhinolaryngol Head Neck Surg 2019; 4: 1-5. DOI: 10.15761/OHNS.1000199

1. Stoyanov V, Vlaykov A, Mihailov D, Dimov P. Orbital complications of Functional Endoscopic Sinus Surgery. International Bulletin of Otorhinolaryngology 2014; 10(1): 14-17.

1. Elsisi H. Safety and efficacy of pediatric functional endoscopic sinus surgery for the treatment of pediatric chronic rhinosinusitis. The Egyptian J of Otolaryngol 2017; 33(4): 616-622.

1. Olm MA, Galdini EG, Mauad T. Diagnosis of primary ciliary dyskinesia. J Bras Pneumol 2015; 41(3): 251-263.

1. Rose AS, Thorp BD, Zanation AM, Ebert CS Jr. Chronic rhinosinusitis in children. Pediatr Clin North Am 2013; 60(4): 979-991.

1. McClay JE. Pediatric sinusitis surgery. Otolaryngology and facial plastic surgery. Medscape 2018. https://emedicine.medscape.com/ article/873298-overview\#a7

1. Alvarado J, Stolovitzky P. Management of pediatric chronic rhinosinusitis. Curr Treat Options Allergy 2020; 7: 356-369. https://doi. org/10.1007/s40521-020-00268-6

1. К. Джамбазов, Н. Трайкова. Риносинуитите - често срещана, но неразпознаваема патология в кърмаческата и малката възраст. Изд. Контекст, 2011 г.

1. Badr DT, Gaffin JM, Phipatanakul W. Pediatric Rhinosinusitis. Curr Treat Options Allergy 2016; 3(3): 268-281.

1. Попов Т. Ендоскопски операции на синусите при пациенти под 18 години - клиничен случай и обзор. УМБАЛ „Царица Йоанна-ИСУЛ“. 2016: https://prezi.com/hnevjhqnswp5/18/

1. Siddiqui S, Tahiri M, Gupta A,Nam R, Rachmanido A. The management of paediatric rhinosinusitis. Int J Pediatr Otorhinolaryngol 2021; 147: 110786. doi: 10.1016/j.ijporl.2021.110786.

Reviewer of the article: Prof. Dr. Karen Dzhambazov, MD, PhD, Medical University - Plovdiv

\author{
Correspondence to: \\ Boris Duhlenski, MD \\ Clinic of Otorhinolaryngology, University Hospital "Dr. Georgi Stranski" - Pleven \\ II Clinical Base, 91 Gen. Vladimir Vazov Str., Pleven 5800 \\ Email:duhlenski_b@abv.bg; Mobile phone: +359886804296
}

